\title{
An Innovative Approach to Observational Field Experiences in Higher Education
}

\author{
Elizabeth Block, Abbie Burt, Tiffany Papa, Leah Peterson, Gregg Stall, \\ Alyson Theriot \\ College of Education, Nicholls State University, Thibodaux, USA \\ Email: tiffany.papa@nicholls.edu
}

Received September 29 ${ }^{\text {th }}$, 2012; revised October 28 ${ }^{\text {th }}$, 2012; accepted November $13^{\text {th }}$, 2012

\begin{abstract}
Field experiences within teacher education programs are vital aspects of the higher education experience. The purpose of this article is to examine students' perceptions of classroom-based field experiences and to determine the role that technology-based field experiences may play in institutions of higher education. The survey data indicate that while candidates perceive that classroom-based field experiences are invaluable in defining their professional choices, the data also indicated positive candidate perceptions of technology-based field experiences. Candidate focus group responses indicated that a combination of both classroom and technology-based field experiences are beneficial to candidates in teacher preparation programs. The implications of this study indicate that future research must be conducted as to the manner in which technology-based field experiences may be enriched in higher education.
\end{abstract}

Keywords: Observations; Technology-Based; Classroom-Based; Field Experiences; Higher Education

\section{Introduction}

Field experiences within education programs are imperative elements in teacher preparation (Kale \& Whitehouse, 2011). Clinical-based exposure provides examples of best practices while offering various benefits to candidates. With quality field experiences, candidates are able to apply the knowledge they have gained from coursework in an actual classroom setting. Through observations and lesson implementation, candidates can reflect on their experiences and gain insight into their own personal teaching styles (Ferber \& Nillas, 2010). In “Transforming Teacher Education through Clinical Practice: A National Strategy to Prepare Effective Teachers," commissioned by NCATE (2010), the authors describe new techniques to revamp candidate experiences:

But teaching, like medicine, is a profession of practice, and prospective teachers must be prepared to become expert practitioners who know how to use the knowledge of their profession to advance student learning and how to build their professional knowledge through practice. In order to achieve this we must place practice at the center of teaching preparation (NCATE, 2010: p. 2)

This experience in the field, also described in the article as clinical practice, should be thoroughly incorporated within candidates' educational programs. It is impossible to extricate the pedagogy from practice as they "are woven throughout preparation, in course work, in laboratory-based experiences, and in school-embedded practice" (NCATE, 2010: p. 5). It is necessary for candidates aspiring to become teachers to have valuable field experiences to observe, acquire, and practice the skills necessary to become successful. Field experience is an influential and indispensable part of teacher education preparation.

Although field experiences are important components of teacher education, the manner in which these experiences are executed dramatically affects their value and significance. Tradi- tionally, candidates were sent into the field to conduct all observations and teaching experiences. While these classroom-based experiences are invaluable, they place a burden on the institution of higher education to organize and assign placements for each candidate in multiple classes. These classroom based-experiences also require that district schools manage the traffic of candidates on their campuses.

A current trend in streamlining and enhancing field-based experiences is the integration of technology in teacher preparation. Technology has a thriving existence within education (Hixon \& So, 2009) from pre-kindergarten through twelfth grade. NCATE (2010) addressed the importance of clinical-practice as well as the integration of technology in its eighth design princeple:

Technology applications foster high-impact preparation: Stateof-the-art technologies should be employed by preparation programs to promote enhanced productivity, greater efficiencies, and collaboration through learning communities. Technology should also be an important tool to share best practices across partnerships, and to facilitate on-going professional learning (p. 6).

With the boost in educational programs in the United States, institutions are forced to increase the number of candidate placements enlarging the assignment area. This entails candidates and faculty to travel further distances to achieve field experience requirements which, in return, has major implications on both time and money spent (Hixon \& So, 2009). Additional apprehension arises when trying to make certain candidates gain experience, not only in the field, but also in diverse classroom settings. With the appropriate technology integration, these concerns can be properly addressed.

There are advantages to both classroom-based field experiences and technology-enhanced or virtual field experiences. The inclusion of both types of field experiences improves the opportunity for candidates to observe various classroom settings, tea- 
ching styles, strategies, and diverse populations. Alternatively, when candidates are limited to one placement in the field, it hinders their ability to observe different environments. When candidates observe or teach in different classrooms, it produces multiple experiences within the class which may limit class discussion around a common experience. Candidate participation in classroom discussions, especially at the freshman and sophomore levels, is more challenging when there is not a common observation environment at the center of the discussion. It is through this dialogue and reflection of field experiences that candidates are able to further their knowledge, skills, and dispositions as future educators.

Understanding the needs of society, as well as the needs of teacher candidates, is essential in designing strong educational experiences for teacher candidates. Chang (2009) noted that "Understanding teacher candidates' concerns is an enormous step towards a strong teacher education program, and addressing these concerns is the ultimate goal of teacher educators" (p. 24). Additional research is required in order to compare the effectiveness and efficiency of various field experience models and the disposition of teacher candidates toward those models. The gap between theory and practice will not diminish instantaneously as a direct result of field experience participation, and "one should not assume that all field experiences will actually help bridge the theory-practice gap that merely requiring more field experience is necessarily better" (Capraro, Capraro, \& Helfedlt, 2010: pp. 131-132). The quality of the field experience environment and the effectiveness of its contribution to teacher education programs should be the focus for future study. Clinical-based practice can offer unlimited teacher preparation benefits if implemented properly within the educational setting.

Since studies have shown that field experiences in the classroom setting are beneficial to the teacher candidate (Edwards, 1996), many teacher preparation programs have incorporated a vast number of field experiences (Adcock \& Austin, 2002) within their teacher preparation programs. Some universities organize these field work/observations by level according to the activities assigned to the candidate. For example, a Level One field experience is simply observing a lesson implementation in the field; a Level Two field experience increases the candidate's responsibility by delegating tutoring, interviews, or small group lesson implementations completed by the candidate; and a $L e$ vel Three field experience extends the candidate even more by having him or her implement a lesson to the entire class. NCATE (2010) stated that clinical practice (Level Two and Level Three field experiences) is valuable in that it provides the candidates with hands-on experiences working with the children for whom they will be responsible. In reference to this information, the committee has decided that the focus of this study will be on Level One field experiences.

With regard to Level One field experiences as observations, several issues need to be addressed: the time commitment of candidates in field observations; the liability issue of on-site observation visits; the access to diverse candidate populations; and management of safety in the schools (Adcock \& Austin, 2002). Because of these concerns, teacher preparation programs are currently seeking alternative methods for enhancing and enriching classroom-based observation experiences. Educators also recognize the importance of integrating technology in the highessional careers (Adcock \& Austin, 2002) making technologybased observations an ideal fit for Level One field experiences.

At the University of Nebraska, federal grant money was se- cured for a two-way audio/video conferencing system. This system allows for two-dimensional viewing of the school classroom through a camera that includes picture and sound. The professor has remote camera controls that allow for tracking of the classroom throughout the lesson. The remote video observation can be taped, which gives the university classes flexibility for viewing during class time or at a later date, as well as accommodating children's classroom schedules. In this study, university candidates observed on-site during the first part of the semester. Later in the semester, observations were completed using the two-way conferencing system from the university classroom. In an interview process, the candidates were asked to compare their remote and their on-site experiences. The university candidates felt their experiences via technology were more beneficial than the on-site experience (Adcock \& Austin, 2002).

This type of blended method using classroom based and technology based field experiences has attractive qualities for both candidates and faculty. Unfortunately, innovation in technology can be seen as a weakness in many higher education institutions due to budgetary challenges. With a transforming candidate population, it is a practical and opportune time to implement changes with regard to field experiences. With new technological advancements, there are multiple ways to improve current methodologies and provide a higher quality of field experiences for teacher candidates. Kale \& Whitehouse (2011) stated that due to the transforming candidate population, "there is a need to design and examine the effectiveness of video cases that foster pre-service teachers' problem-solving skills” (p. 4360). In the past, teacher candidates have been limited to their practice, particularly field experiences, because of inadequate opportunities. With careful consideration of both classroom-based and technology enhanced field experiences, these candidates can become well-versed in a multitude of scenarios before entering a particular field. Kale and Whitehouse (2011) found that video analyses and technology enhanced observations can significantly increase pre-service teachers' understanding of classroom events. With the changing needs of the candidate population in mind, a balance of traditional and technological observational opportunities can be developed as an effective environmental design for the preparation of future educators. "Such video cases may have the potential to foster problem-solving skills,” (p. 4360) as Kale and Whitehouse (2011) explained and then added, "especially when future teachers are directed to identify issues and generate possible teaching strategies arising from their analysis of the video case” (p. 4360). Technology-enhanced field experiences in combination with the traditional classroom setting are vital for teacher candidate success.

As with the implementation of any new process, there are barriers to overcome. One option for Level One field experiences is video conferencing. This method presents the challenge of obtaining and installing equipment. The video conferencing equipment requires access through the school's internet firewall. School technicians must make the necessary arrangements, which can be time-consuming and burdensome if the school's technical support staff is not fully knowledgeable about firewalls. Additionally, the internet access must be powerful enough to ensure a stable connection that will prevent pauses in transmission. Audio problems can also limit observations and interactions. Lastly, both the school staff, as well as the university faculty, must be trained in the proper usage of such equipment which, once again, is costly and time-consuming (Lehman \& Razzouk, 2002). 
A cutting edge methodology in teaching via video conferencing is the virtual teaching experience (Vavasseur, 2012). In a virtual teaching experience, candidates prepare a lesson that involves interactive songs, books, stories, puppet shows, or other age appropriate activities. The candidates record themselves teaching the lesson using strategies that are often seen on children's television programming. For example, the candidate may ask the students if they can identify a shape illustrated in a book. The candidate then pauses for several seconds while s/he pretends to listen to the students' responses. This wait time technique is often seen in shows such as "Blue's Clues" and "Sesame Street." Once the lesson is recorded, it is uploaded to YouTube and broadcasted to participating classrooms at a pre-determined time or at the teacher's convenience. This form of virtual teaching allows candidates to prepare a lesson that is creative and well developed without the challenges of transportation as the lesson can be shared with hundreds of participating schools. This experience is ideal for candidates who are at the beginning of their programs as they are not challenged by classroom management issues. This form of "teaching" could not exist in isolation of traditional implemented lessons in the classroom. Candidates must obtain practice teaching a lesson while contending with classroom management, real-time responses from students, unplanned digressions from the lesson plan and interpersonal differences. Virtual teaching allows for multiple modes of lesson implementation, but it is necessary to combine these technology-based experiences with classroom-based experiences to develop the "whole" teacher.

Another method for technology-based field experiences is creating a digital library of teaching experience videos. This library allows faculty to review multiple teaching vignettes and select examples that best illustrate the content being taught. These videos, however, must be created, edited for content, uploaded, and/or secured from a reputable source. In addition, it is necessary to obtain parental consent for all of the students who are visible in the video. This is a labor intensive process which involves a faculty member who is well versed in the learning objectives for each video field experience. The end result, however, has its rewards. As Hixon and So (2009) explained, "Technology may be a viable option to increase access to quality classrooms embodying types of pedagogical practices consistent with educational reform, and to encourage preservice teachers to explore new ideas in a safe environment” (p. 301). Although there is extensive preparation on the front end of implementing technology enhanced observations, there seems to be a significant payoff for candidates, faculty, and cooperating school districts that employ these future educators (Hixon \& So, 2009).

Based on the need to preserve the integrity of field experiences while remaining current with technological trends in the field, the authors began examining the delivery of Level One field experiences in January, 2011. The College of Education at Nicholls State University had a well-developed field experience process by which candidates were placed in Level One, Two, and Three field experiences by a field experience coordinator. Care was taken to ensure that candidates observed and taught at various schools in order to guarantee diversity in experiences and in student populations. At the time that the authors first met to discuss field experiences, professors implemented field experiences based on the goals and standards of accrediting agencies, national organizations and the objectives of the course. Most professors implemented traditional Level One field ex- periences in their coursework where candidates observed in traditional classrooms. Many professors were using videos or other technology-based observations to supplement classroombased observations. Some professors utilized technology-based observations in lieu of classroom-based observations. There was no policy in place dictating the manner in which observations were to be conducted. The authors decided that it was imperative to obtain feedback from candidates and faculty on their perceptions of classroom-based and technology-based observations. It was decided that surveys and focus groups would be the most effective means of gathering data on perceptions of field experience observations.

\section{Methodology}

In designing the survey, the authors included questions related to the process of obtaining field experiences in addition to the candidates' perceptions on classroom-based versus technology-based field experiences. The complete survey is included in Appendix A. The survey was designed on a Likert scale with five measures: 1) Strongly Agree, 2) Agree, 3) Neutral, 4) Disagree, 5) Strongly Disagree. The first two questions of the survey established demographic information on the candidates (major and classification). Questions three through thirteen were included to determine candidates' perceptions of obtaining field experiences via the field experience coordinator or independently. Questions fourteen through nineteen were included to determine candidates' perceptions on classroom-based experiences in relation to professional choices, classroom management skills, lesson implementation, the teacher/student relationship, feelings about becoming a teacher, and the view of teaching as a profession. Questions twenty-one through twenty-seven were based on the above italicized domains but in relation to candidates' perceptions on technology-based experiences.

The survey was administered in selected courses that represented freshman, sophomore, junior, and senior level candidates. The courses in which candidates were surveyed included EDUC 250 (Introduction to Elementary and Secondary Education), EDUC 312 (Planning for Teaching in Multicultural Classrooms), FCED 335 (Birth to Five: Movement and Music), EDUC 365 (The Teaching of Reading and Language Arts in the Elementary School), EDUC 402 (Reading Instruction in the Elementary School), and FCED 435 (Management of Birth to Five Programs). All of these courses are housed in the Teacher Education Department in the College of Education. The surveys were distributed by the course instructors in the first week of April, 2011.

In addition to survey data, the authors wished to obtain more in-depth feedback on field experiences by holding four focus groups. The following courses were selected for the focus groups as they represented each level of classification within the college: EDUC 250, EDUC 365, and FCED 435. Education 250 is the first class in which candidates enroll upon passing Praxis I and being admitted into the College. Education 365 and FCED 435 are junior and senior level courses that include candidates with experiences in both classroom and technologybased observations. These focus groups were held in the second and third weeks of April, 2011, and they were each conducted by two of the authors who were not the instructors of the course. Rather than asking for volunteers from the class to participate in the focus group, the facilitators randomly selected fourteen candidates from each class and invited these candidates to meet 
in another classroom. The focus groups were recorded with a digital recorder to allow for later transcription of the data and also to relieve the facilitators of note taking during the focus groups. The authors developed four over-arching questions with sub-questions that related to classroom-based and technologybased observations. The questions are included in Appendix B. The same questions were asked in each focus group, and the candidates were given ample time to contribute in an open and casual environment. At the outset of the focus groups, the candidates were encouraged to give candid responses and were assured that the information would remain anonymous.

With three focus groups established for candidate perceptions of field experiences, the authors felt that it was important to conduct a focus group on faculty perceptions of field experiences. The four faculty members conducting the research were not included in the faculty population. Of the twelve remaining faculty members, six were selected by a random drawing. These six individuals were e-mailed by the Assessment Coordinator and invited to participate in the focus group in late April, 2011. All six faculty members were present at the focus group. The focus group was facilitated by the Assessment Coordinator and a Graduate Assistant in order to encourage honest feedback. The facilitators asked five over-arching questions developed by the authors that closely paralleled those asked of candidates. The questions are included in Appendix C. The participants were ensured of their anonymity and the focus group was digitally recorded for later transcription.

\section{Results}

Surveys were completed by 97 candidates, and data was analyzed in May, 2011. Table 1 illustrates the percentages of candidates who responded to each subscale on the Likert scale. Questions pertaining to the logistics of obtaining field experiences were removed. The remaining questions relate to candidates' perceptions of classroom-based and technology-based observations.
Survey questions measured students' agreement on the impact of classroom-based field experiences and technology-based field experiences on the following areas: professional choices, future classroom management skills, future lesson implementation, view of the teacher/student relationship, feelings about becoming a teacher, and teaching as a profession. Student responses were condensed into three categories of agreement: strongly agree/agree; neutral; and disagree/strongly disagree.

The authors hypothesized that student survey responses would reflect that classroom-based experiences had a much greater impact on professional development than technology-based experiences. Table 1 compares student responses on survey questions concerning classroom experiences and those concerning technology experiences. Although more than $85 \%$ of student responses indicate that classroom-based experiences affected them in all areas, at least $80 \%$ of student responses showed that technology-based experiences also had an impact in all areas except for professional choices (74\% of responses).

A paired samples $t$ test was conducted to compare student responses on classroom experience questions and technology experience questions. A numeric value, one through five, was assigned to each subscale of the Likert scale. Responses marked as Strongly Agree were given a one, and responses marked as Strongly Disagree were given a five. The analysis revealed a significant difference between the means of student responses for classroom $(\mathrm{M}=13.26, \mathrm{SD}=4.02)$ and for technology $(\mathrm{M}=$ $19.11, \mathrm{SD}=5.77$ ) experiences; $\mathrm{t}(124)=-10.73, p<.001$ (see Table 2). These results suggest that there is a difference between the two types of field experiences. More specifically, classroom experiences had a greater impact on students than technology experiences.

In transcribing the candidate focus groups, several themes emerged to the authors (see Table 3). The authors grouped feedback into the following emerging themes: Real World Experiences, Professional Growth, and Convenience. Responses classified under Real World Experiences related positively to classroom-based field experiences in that candidates stated that sit-

Table 1.

Educational field experience survey results.

April 2011

\begin{tabular}{lcc}
\hline Impact on Professional Choices & Classroom Based & Technology Based \\
\hline Strongly Agree and Agree & $63.9 \%$ & $35.0 \%$ \\
Neutral & $27.8 \%$ & $39.2 \%$ \\
Disagree and Strongly Disagree & $8.3 \%$ & $25.7 \%$ \\
\hline Impact on Future Classroom Management Skills & Classroom Based & Technology Based \\
\hline Strongly Agree and Agree & $73.2 \%$ & $50.5 \%$ \\
Neutral & $19.6 \%$ & $33.0 \%$ \\
Disagree and Strongly Disagree & $7.2 \%$ & $16.5 \%$ \\
\hline Impact on My Future Lesson Implementation & Classroom Based & Technology Based \\
\hline Strongly Agree and Agree & $50.5 \%$ & $58.7 \%$ \\
Neutral & $37.1 \%$ & $33.0 \%$ \\
Disagree and Strongly Disagree & $12.4 \%$ & $8.3 \%$ \\
Impact on View of the Teacher/Student Relationship & Classroom Based & Technology Based \\
\hline Strongly Agree and Agree & $73.2 \%$ & $44.4 \%$ \\
Neutral & $17.5 \%$ & $38.1 \%$ \\
Disagree and Strongly Disagree & $9.2 \%$ & $17.5 \%$ \\
\hline Impact on Feelings about Becoming a Teacher & Classroom Based & Technology Based \\
\hline Strongly Agree and Agree & $60.8 \%$ & $38.1 \%$ \\
Neutral & $25.8 \%$ & $42.3 \%$ \\
Disagree and Strongly Disagree & $13.4 \%$ & $19.6 \%$ \\
\hline Impact on View of Teaching as a Profession & Classroom Based \\
\hline Strongly Agree and Agree & $66.0 \%$ & Technology Based \\
Neutral & $24.7 \%$ & $48.4 \%$ \\
Disagree and Strongly Disagree & $9.3 \%$ & $37.1 \%$ \\
\hline
\end{tabular}


Table 2.

T-test comparing students' perceptions of classroom and technology-based field experiences.

\begin{tabular}{ccccc}
\hline \multicolumn{5}{c}{ Student Rating Means for Classroom and Technology Experiences } \\
\hline \multicolumn{5}{c}{ Experience Type } \\
Classroom & Technology & $\mathrm{t}$ & $\mathrm{df}$ \\
\hline Rating of Impact & 13.26 & 19.11 & $-10.73^{*}$ & 124 \\
& $(4.02)$ & $(5.77)$ & & \\
\hline
\end{tabular}

Note: ${ }^{*}=p<.01$. Standard Deviations appear in parentheses below means.

ting in the actual classroom and absorbing the context of the school was an important learning experience. The majority of the responses relating positively to classroom-based observations were classified as Real World Experiences. In one focus group, a candidate stated that she feels she learned more from observing teachers interact with students, parents, colleagues, and administration before and after the actual lessons. Classroom-based field experiences immerse candidates in the context of the schools and classrooms and help to shape future knowledge, skills, and dispositions. While the authors found positive comments related to Real World Experiences in classroombased field experiences, they found that technology-based field experiences were lacking in these Real World Experiences. Candidates stated that in most technology-based field experiences, the camera was filming the lesson itself which did not allow for observation of classroom or school contextual factors.

The second theme that emerged from the focus groups was that of Professional Growth. Interacting with teachers and other individuals at each school helped candidates grow in knowledge, skills, dispositions and making decisions about future employment. While Professional Growth was an emergent positive theme under classroom-based field experiences, it also emerged as a negative theme in this domain. Candidates indicated that quantity of observations assigned did not equal quality. In other words, the candidates felt that observing in multiple classrooms over their educational careers was not always the best use of time. While they indicated that observations were invaluable and very important to their development as a professional, they reached a threshold where observations became redundant and too costly in terms of transportation and time. Focus group participants indicated that technology-based observations provided uniform field experiences to the entire class which enriched classroom discussion and subsequent learning due to these shared experiences. The authors categorized these responses under Professional Growth since the candidates indicated that the uniformity of the experience allowed for deeper discussion of specific topics, whereas most professors did not create class discourse on classroom-based experiences since each candidate had such disparate observations. The theme of Professional Growth was also applied to technology-based field experiences as candidates cited that this format helped them feel more comfortable in using technology in their future classrooms. Candidates did indicate that a lack of assignment structure for some technology-based field experiences hindered their growth. For this reason, Professional Growth was listed as a negative theme for technology-based field experiences.

The third theme that emerged from the candidate-based field experiences was that of Convenience. Convenience was cited as a negative theme in classroom-based field experiences and as both a positive and negative theme in technology-based field experiences. The time allocated to obtaining classroom-based placements in multiple courses during one semester was consis- tently cited by candidates as a negative aspect of classroombased field experiences. Many candidates at Nicholls State University must assume numerous roles including that of employee, family caretaker, and student. For this reason, classroom-based field experiences impose a financial burden with regard to leave time from work as well as gas mileage. The focus group candidates indicated that the technology-based observations allowed non-traditional or working candidates to maintain their schedules at work and at the university as most of these technologybased observations could be accessed and completed at one's discretion. While the general response to using technology for observations was positive amongst the focus group participants, they expressed frustration over time wasted when the technology failed. For example, some candidates cited problems with observations during which they observed a classroom via video conferencing. There were multiple occasions when the camera in the K-12 classroom was aimed at a wall so that students were not even visible. Other times, the teacher in the classroom struggled to connect with the professor at the university so that the lesson could be remotely transmitted. For these reasons, Convenience was both positively and negatively cited as a theme in technology-based field experiences.

The faculty focus group was less illustrative of the positive and negative themes associated with field experiences; rather, faculty members' responses indicated an appreciation for classroom-based observations and an eagerness to learn more methods for conducting technology-based observations. Faculty members indicated that with the vast growth in technology, most young candidates respond better to assignments that involve some technological component. Faculty members shared that it is often overwhelming to stay on the cusp of advances in technology so it feels "safer" to continue using traditional assignments. These individuals did express a desire to integrate new technology in coursework and a willingness to attend trainings to facilitate that process.

\section{Future Implications}

The authors approached this research as a preliminary step in gathering information on Level One field experiences in the College of Education. They cast a wide net in gathering data on candidates' and faculty members' perspectives on classroombased and technology-based field experiences including both a survey and focus groups. The authors entered the data collection process with the assumption that candidates and faculty would be more strongly in favor of classroom-based observations than technology-based observations. The survey data supported this assumption in that candidates did rate classroombased field experiences higher than technology-based field experiences, yet the survey data indicate a favorable perception of technology-based field experiences as well. The focus group responses were indicative of a favorable perception toward tech- 
Table 3.

Major themes extracted from student focus groups.

\begin{tabular}{|c|c|c|}
\hline \multirow[b]{2}{*}{$\begin{array}{c}\text { Candidate Focus } \\
\text { Groups }\end{array}$} & $\begin{array}{l}\text { Positive Themes for } \\
\text { Classroom Based } \\
\text { Field Experiences }\end{array}$ & $\begin{array}{l}\text { Negative Themes for } \\
\text { Classroom Based } \\
\text { Field Experiences }\end{array}$ \\
\hline & $\begin{array}{l}\text { "Real” World Experiences } \\
-\quad \text { Observe context of classroom } \\
-\quad \text { Observe all students including those not participating in lesson } \\
-\quad \text { Obtain a "feel” for the schools' climates } \\
-\quad \text { Observe how teacher handles disturbances in schedule } \\
-\quad \text { First-hand exposure to the "real” experiences of teaching } \\
\text { Professional Growth } \\
-\quad \text { Personal access to teachers' insights or feelings } \\
-\quad \text { Professional insight into desirable schools for future employment }\end{array}$ & 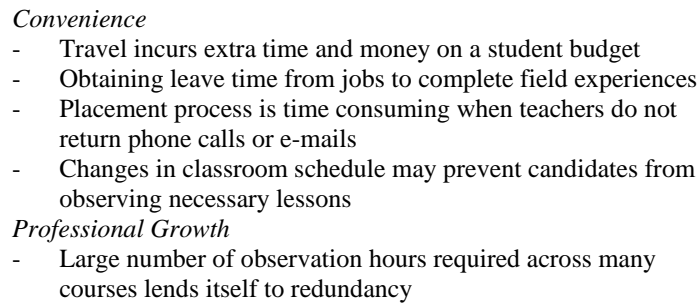 \\
\hline \multirow[b]{2}{*}{$\begin{array}{c}\text { Candidate Focus } \\
\text { Groups }\end{array}$} & $\begin{array}{l}\text { Positive Themes for } \\
\text { Technology Based } \\
\text { Field Experiences }\end{array}$ & $\begin{array}{l}\text { Negative Themes for } \\
\text { Technology Based } \\
\text { Field Experiences }\end{array}$ \\
\hline & $\begin{array}{ll}\text { Convenience } \\
-\quad \text { Convenient } \\
-\quad \text { Cost effective } \\
-\quad \text { Lack of scheduling issues with teachers } \\
-\quad \text { Lack of placement issues with schools } \\
-\quad \text { Limited distractions as videos are edited } \\
\text { Professional Growth } \\
-\quad \text { Uniform lessons allow focus on specific concepts } \\
-\quad \text { Allows for observation of many classes across age } \\
-\quad \text { Feel prepared to use technology in classrooms }\end{array}$ & $\begin{array}{l}\text { Convenience } \\
-\quad \text { Glitches in technology absorb candidates' time } \\
\text { - Live-feeds often fail as teachers do not have camera focused } \\
\text { on children } \\
\text { - Unable to access technology from home computer } \\
\text { Professional Growth } \\
\text { - Lack of structured assignments/questions relating to videos } \\
\text { "Real" World Experiences } \\
\text { - Videos or live-feed were too short or limited in scope to get a } \\
\quad \text { "feel" for the rest of the classroom }\end{array}$ \\
\hline
\end{tabular}

nology-based field experiences. Candidates in these focus groups were quick to elaborate on the positive and negative aspects of both types of field experiences but were very supportive of "growing" the technology-based field experiences into stronger and more enriching experiences. The convenience and the common experience of the technology observations were positively cited by candidates while the frustration involved in technology that failed was cited as the greatest limitation of this format. Candidates in the focus groups suggested that the technologybased observations would be more effective with equipment that always works properly, a structured assignment completed in conjunction with viewing the observation, and dialogue in class during which the professor and candidates share their thoughts on the teaching vignette. Candidates stated that viewing a video in which a teacher presented a lesson was not a helpful learning tool in the absence of guidance from the professor. Candidates want the formal "set-up" for the observation, questions to answer while viewing the observation, and a whole group discussion during which time the professor indicates key concepts in the video. It would be useful for future research in this area to include a more structured approach to technologybased field experiences in which professors imbedded both technology and classroom-based field experiences in course assignments and class discussion to further the professional growth of candidates' knowledge, skills, and dispositions.

\section{Limitations}

Confounding variables were identified during the study that could have created possible vulnerabilities to validity threats. From the candidate focus groups, the authors realized certain subjects had been exposed to technology-based experiences more than others. Even though the authors surveyed and ran- domly interviewed a broad sample of candidates (in terms of major and classification) the candidates' previous experiences with technology-based observations were not readily articulated since the manner of implementation varied across courses and professors. The lack of familiarity with this type of field experience may have had an effect on the survey results as well as the focus group responses also known as the "history effect." Since implementation of technology-based field experiences was not closely monitored in relation to which candidates or classes had the most or least amount of experience with these non-traditional observations, and no guidelines are in place for the method with which technology-based field experiences are delivered, the authors feel that future research must be conducted to determine the efficacy of structured technology-based observations that involve the aforementioned format (Context, Observation, Questions, and Discussion). Using the same pedagogy across courses will allow for true comparison of candidates' perceptions of these experiences, and ultimately a measurement in growth of knowledge, skills, and dispositions as professional educators.

In addition to the "history effect", another possible variable was acknowledged in relation to changes to the variable. Although the surveyed subjects and focus groups that held discussion were treated by the authors without intended bias or persuasion, a possibility of subject threat still existed. Candidates were certainly aware of others' perceptions of field experience whether it be fellow classmates, faculty, or staff. As Jackson (2012) explained, "Many subjects try to be 'good subjects', meaning that they try to determine what the researcher wants and to adjust their behavior accordingly” (p. 235). Although the authors left personal opinions out of the discussion and responses remained anonymous, a possibility remains that indirect actions by the candidates affected some of the results. Bas- 
ing findings on self-reported measures through a survey is convenient but opens the findings up to questions of authentication. Finally, the survey used in this study was not subjected to extensive testing for optimal objectivity. However, the addition of focus groups did increase validity and evidence to support the findings.

Recommendations for future study include more closely monitoring current and past implementation of technology-based observation and how it impacts candidates' perceptions related to traditional observations. Using a survey that has been tested for any biasness or subjectivity is also suggested. The research conducted by the authors is thoroughly contextualized and is meant to contribute mostly to evolving theory within teacher education.

\section{Conclusion}

Through this process, the authors found that the surveyed candidates valued both experiences. In other words, they enjoyed having video-based observations because they could watch the same scenario as their classmates and discuss accordingly. They also appreciated the convenience of the technology-based observation. Additionally, they benefited from the classroombased experiences because they were immersed in the classroom context where they gained perspective on all angles of teaching. While the focus group data demonstrate an unexpected positive perception of technology-based field experiences, the candidates still cited the positive outcomes of traditional classroom-based field experiences. Ultimately, the authors found that university candidates desire a combination of both experiences throughout their educational careers. In future studies, it is important for these authors to determine the manner in which institutions of higher education can best incorporate both forms of field experiences in order to meet the needs of the candidates, remain on the cutting edge of technology, and best serve the students in the K-12 school systems in an efficient and costeffective manner.

\section{REFERENCES}

Adcock, P., \& Austin, W. (2002). Alternative classroom observation through two-way audio/video conferencing systems. Proceedings of 13th Society for Information Technology \& Teacher Education International Conference, Nashville, 18-23 March 2002.

Capraro, M. M., Capraro, M. R., \& Helfeldt, J. (2010). Do differing types of field experiences make a difference in teacher candidates' perceived level of competence? URL (last check 24 September 2012). http://www.eric.ed.gov/PDFS/EJ872653.pdf

Chang, S. H. (2009). Concerns of teacher candidates in an early field experience. Mid-Western Educational Researcher, 22, 19-25.

Edwards, J. (1996). A dose of reality for future teachers. Educational Leadership, 54, 56-57.

Ferber, T., \& Nillas, L. A. (2010). Through the eyes of student teachers: Successes and challenges in field teaching experiences. National Teacher Education Journal, 3, 61-86.

Hixon, E., \& So, H. (2009). Technology's role in field experiences for preservice teacher training. Educational Technology \& Society, 12, 294-304.

Jackson, S. L. (2012). Research methods and statistics: A critical thinking approach. Belmont, CA: Wadsworth, Cengage Learning.

Kale, U., \& Whitehouse, P. (2011). Pre-service teacher learning: Pedagogical content knowledge in video-based problem-solving. In M. Koehler, \& P. Mishra (Eds.), Proceedings of Society for Information Technology \& Teacher Education International Conference 2011 (pp. 4360-4367). Chesapeake, VA: AACE.

Razzouk, R., \& Lehman, J. (2002). Video conferencing as a tool to link colleges of education with K-12 schools: A P3T3 project initiative. In D. Willis et al. (Eds.), Proceedings of Society for Information Technology \& Teacher Education International Conference 2002 (pp. 2424-2425). Chesapeake, VA: AACE.

National Council for Accreditation of Teacher Education (2010). Transforming teacher education through clinical practice: A national strategy to prepare effective teachers. Washington: NCATE Publications.

Vavasseur, C. (2012). Teach me how to tech: Video conferencing in the classroom. Eugene: Visions Technology in Education. 


\section{Appendix A}

Thank you for participating in this survey on field experiences in the Department of Teacher Education at Nicholls State University. Please answer each question by bubbling in the corresponding letter of your choice on the scantron sheet.

Demographic Information

1) What is your declared major?

a) B-5/Early Interventionist Education (BFED)

b) PreK-3rd grade

c) 1 - 5 Elementary Education

d) 4 - 8 Middle School

e) Secondary Education (math, English, science, social studies, FACS, music, art, business)

2) What is your classification?

a) Freshman

b) Sophomore

c) Junior

d) Senior

Section I of this survey includes questions about the process of obtaining field experiences. Think back to the last class in which the field experience coordinator (i.e. Alyson Theriot) placed you for your field experiences. Answer the following questions about your experiences:

3) Have you taken an education course that required you to see the field experience coordinator (i.e. Alyson Theriot) for Field Placements? (If yes, please answer questions 4 - 6. If no, please skip to question 7)

a) Yes

b) No

4) I found the field placement process (completing required paperwork, receiving placement, visiting school(s) to drop off paperwork, communication with teacher(s), completion of assignment) to be complicated.
a) Strongly Agree
b) Agree
c) Neutral
d) Disagree
e) Strongly Disagree
5) After I dropped off the required paperwork at my assigned school(s), I was contacted by the teacher in a timely manner, ensuring completion of the assignment by the due date.

a) Strongly Agree

b) Agree

c) Neutral

d) Disagree

e) Strongly Disagree

6) The process of acquiring my field placement through the field experience coordinator (i.e. Alyson Theriot) influenced my overall experience in the field.
a) Strongly Agree
b) Agree
c) Neutral
d) Disagree
e) Strongly Disagree

Think about the courses in which you are currently enrolled that require you to find your own field placements. Answer the following questions about your experiences:

7) Are you taking an Education course in Spring, 2011 in which you are required to seek out your own field placements? (If yes, please answer questions 8-10. If no, please skip to ques- tion 11).

a) Yes

b) No

8) I found the current field placement process (finding my own placement and turning in the required paperwork to the field experience coordinator and/or my instructor) to be complicated.

a) Strongly Agree

b) Agree

c) Neutral

d) Disagree

e) Strongly Disagree

9) After finding a placement for my field experience(s) I communicated with my teacher in a timely manner, ensuring completion of the assignment by the due date.
a) Strongly Agree
b) Agree
c) Neutral
d) Disagree
e) Strongly Disagree

10) The process of acquiring my own field placement influenced my overall experience in the field.
a) Strongly Agree
b) Agree
c) Neutral
d) Disagree
e) Strongly Disagree

Section II of this survey includes questions about the Format of Field Experiences. Think back to the courses in which you completed Level I Observations. Answer the following questions about your experiences:

11) I have found classroom based observations (observing in a classroom in the field) to be a valuable learning experience in my education courses.

a) Strongly Agree

b) Agree

c) Neutral

d) Disagree

e) Strongly Disagree

12) Transportation (access to and/or cost) for classroom based observations is a hardship.

a) Strongly Agree

b) Agree

c) Neutral

d) Disagree

e) Strongly Disagree

13) I believe that the ideal number of observation hours is per course.

a) Zero (0) observation hours

b) 1 - 3 observation hours

c) 4 - 6 observation hours

d) 7 - 10 observation hours

e) More than 10 observation hours

14) Classroom based observations significantly impact my professional choices (age, grade level, population that I wish to teach).
a) Strongly Agree
b) Agree
c) Neutral
d) Disagree
e) Strongly Disagree

15) Classroom based observations significantly impact my 
future classroom management skills.
a) Strongly Agree
b) Agree
c) Neutral
d) Disagree
e) Strongly Disagree
16) Classroom based observations significantly impact my future lesson implementation.
a) Strongly Agree
b) Agree
c) Neutral
d) Disagree
e) Strongly Disagree
17) Classroom based observations significantly impact my view of the teacher/student relationship.
a) Strongly Agree
b) Agree
c) Neutral
d) Disagree
e) Strongly Disagree
18) Classroom based observations significantly impact my feelings about becoming a teacher.
a) Strongly Agree
b) Agree
c) Neutral
d) Disagree
e) Strongly Disagree
19) Classroom based observations significantly impact my view of teaching as a profession.
a) Strongly Agree
b) Agree
c) Neutral
d) Disagree
e) Strongly Disagree

Think about the courses in which you are currently enrolled, or have taken in the past, that require you to complete technology based observations (digital observations on Blackboard, video observations in class, virtual field experiences via a live feed, etc). Answer the following questions about your experiences:

20) Have you taken, or are presently enrolled in an Education course that requires you to complete technology based observation(s) (digital observations on Blackboard, video observations in class, virtual field experiences via a live feed, etc)? (If yes, please answer questions 21 - 27. If no, please skip to question 28).

\section{a) Yes}

b) No

21) I have found technology based observations to be a valuable learning experience in my education courses.
a) Strongly Agree
b) Agree
c) Neutral
d) Disagree
e) Strongly Disagree
a) Strongly Agree
b) Agree
c) Neutral
d) Disagree

22) Technology based observations significantly impact my professional choices (age, grade level, population that I wish to teach). e) Strongly Disagree

23) Technology based observations significantly impact my future classroom management skills.
a) Strongly Agree
b) Agree
c) Neutral
d) Disagree
e) Strongly Disagree

24) Technology based observations significantly impact my future lesson implementation.

a) Strongly Agree

b) Agree

c) Neutral

d) Disagree

e) Strongly Disagree

25) Technology based observations significantly impact my view of the teacher/student relationship.
a) Strongly Agree
b) Agree
c) Neutral
d) Disagree
e) Strongly Disagree

26) Technology based observations significantly impact my feelings about becoming a teacher.
a) Strongly Agree
b) Agree
c) Neutral
d) Disagree
e) Strongly Disagree

27) Technology based observations significantly impact my view of teaching as a profession.

a) Strongly Agree

b) Agree

c) Neutral

d) Disagree

e) Strongly Disagree

28) If given a choice of observation format in my education classes, I would choose the following:

a) Classroom based observations ONLY (in the field)

b) Technology based observation ONLY (digital observations on Blackboard, video observations in class, virtual field experiences via a live feed, etc)

c) A combination of classroom and technology based observations

\section{Appendix B}

\section{Focus Group Questions on Level I Field Experiences}

- Introductions.

- Purpose of focus group is to gather candidates' opinions on level I field experiences (observations) in teacher education courses.

- Process is informal and names will not be attached to responses.

- All responses are anonymous.

- Recording the discussion for a record of comments.

1) We would first like to ask you for some feedback or input on Classroom Based observations in the schools.

a) What do you all see as the advantages of classroom based observations?

b) What do you see as the disadvantages of classroom based observations? 
2) We would like to ask you for some feedback on technology based observations. Examples of technology based observations include: classroom observations via a live feed, digital observations on BB, video observations in class.

a) What type of technology based observations have you experienced and what do you see as the advantages of those observations?

b) What do you see as the disadvantages of technology based observations?

3) We would like to ask for feedback on your ideas for improving the observation learning experience.

a) How do you think classroom based observations could be improved?

i) Probe candidates if they only focus on logistics and not learning/outcomes.

b) How do you think technology based observations can be improved?

i) Probe candidates if they focus on logistics and not learning/outcomes.

4) After completing observations, some professors require a summary, reflection, or discussion in class.

a) We would like your input on how classroom based observations were used or integrated into your college course.

b) Tell us how technology based observations were used or integrated into your class by your professor.

\section{Appendix C}

\section{Faculty Focus Group Questions on Level I Field Experi-} ences

- Introductions

- Purpose of focus group is to gather faculty opinions on level I field experiences.

- Process is informal and names will not be attached to responses.
- All responses are anonymous

- Recording the discussion for a record of comments

1) We would first like to ask you for your feedback on Classroom Based observations in the schools.

a) What do you think are advantages of classroom based observations?

b) What do you see as the disadvantages of classroom based observations?

2) We would like to ask you for some feedback on technology based observations.

a) What type of technology based observations have you used in your classes?

b) What do you think are the advantages of those observations?

c) Where do you see technology based observations going in the future?

d) What do you see as the disadvantages of technology based observations?

e) What are the barriers to using technology based observations?

3) We would like to ask for feedback on your ideas for improving technology based observations/field experiences.

a) How do you think technology based observations can be improved?

4) After completing observations, some professors require a summary, reflection, or discussion in class.

a) How do you integrate classroom based observations in your courses?

b) How do you integrate technology based observations in your courses?

5) Do you think the Level I Field Experiences should involve classroom based observations only, technology based observations only, or a "combination of both?" 